\title{
APPLYING BENFORD'S LAW BY TESTING THE GOVERNMENT MACROECONOMICS DATA
}

\author{
[Využití Benfordova zákona při testování makroekonomických dat vlády]
}

\author{
Michal Plaček ${ }^{1}$ \\ ${ }^{1}$ SVŠE Znojmo,Department of finance and accounting, Loucká 21 \\ E-mail: placek@svse.cz
}

\begin{abstract}
This article builds on research published in the article "Fact and Fiction in EU Governmental Economics Data" (Rauch, Göttsche, Brähler, 2011). By exploring the possibilities of applying Benford's Law as a useful instrument for detecting data manipulation, this instrument is applied to the Czech Republic, particularly in the monthly data of exports and imports for the period 1996-2012, which make up the trade balance. We use the $\mathrm{Z}$ test as the test criterion and the first and second digits are tested. The primary aim of the article is to summarize the current theory regarding Benford's Law and the practical applications of this theory to the governmental macroeconomic data.
\end{abstract}

Keywords: Benford's law, Z test, Government data, manipulation.

JEL classification: $\mathrm{C} 16, \mathrm{E} 01, \mathrm{M} 42$

Doručeno redakci: 10.6.2013; Recenzováno: 3.7.2013; 2.6.2014; Schváleno k publikování: 23.9.2014

\section{Introduction}

The article "Fact and Fiction in EU Governmental Economics Data" (Rauch, Göttsche, Brähler, 2011) which was published in the German Economics Revue was one of the first applications of Benford's Law on the government economic data. Before the aforementioned article, the articles "On the Application of Benford's Law of the International Macroeconomic Statistics" (Nye, Moul, 2007) and (Gonzales-Garcia, Pastor, 2009), which confirmed the theory (Nye, Moul, 2007). Within these, the application is focused mainly on accounting and tax issues e.g. (Carslaw, 1998); (Nigrini, 1997), mathematics (Hill, 1998), (Morrow, 2009), and examining the results of elections (Decker, Myagkov, Ordeshook, 2011) and last but not least, the credibility of scientific results such as regression coefficients (Diekmann, Jann, 2010).

In the article "Fact and Fiction in EU Governmental Economics Data," the authors focused on the economic data of the EU-27 from 1999 to 2009. Instead of the convergence test with Benford's distribution, they evaluate data of states according to the extent of the deviation of their data from Benford's distribution. Within this context, the following data were tested:

- Government deficit and debt

- Government revenue, expenditure and main aggregates

- GDP and its main components

- Balance sheet, consolidated assets and liabilities

The resulting findings were that EU countries, especially Greece, show a significant deviation from Benford's data distribution. The problems of the Greek national accounting confirmed further development. Among the states collectively known as PIGS, test data revealed significant deviations from Benford's distribution only in Ireland. If we focus on the Czech Republic, the authors showed the smallest means of the chi-square test. 


\section{Theory of Benford's law}

The first mention of Benford's Law, originally also called the "First digit law" was made by the American astronomer Simon Newcomb in 1881 in an article entitled "Note on the Frequency of Use of the Different Digits in Natural Numbers" in The American Journal of Mathematics. The article says that the probability that the first digit being the number 1 is $0.111(1: 9=0.1111)$, as we might expect, but 0.301 . This thesis was rediscovered by Frank Benford in the article "The Law of Anomalous Numbers" in Proc.Amer. Phil. Soc 78, pp. 551-572, who dealt with this problem more systematically and surveyed more than 20,000 data samples (Barrow, 2011).

The mathematical applications of Benford's law are mainly dealt with by Theodore Hill (For further details refer to: (Berhger, Hill, 2011)). We can consider the following fundamental theorem as being essential: "If it is chosen as a random distribution, and if from any such distribution given a random sample, significant numbers from this distribution converge to the logarithmic distribution alias Benford's distribution."

Probability of the first digit D1 according to Benford's distribution:

$P(D 1=d l)=\log \left(1+\left(\frac{1}{d 1}\right)\right) \quad d 1 \in\{1 \ldots 9\}$

Probability of the second digit D2 according to Benford's distribution:

$P(D 1=d 1)=\log \left(1+\left(\frac{1}{d 1 d 2}\right)\right) \quad d 1=1 \quad d 2 \in\{1 \ldots 9\}$

If we extend our analysis to the occurrence of the number on $n$ the positon, we will use this general formula:

$$
P_{n}\{d\}=\frac{1}{\ln (B)} \sum_{k=B^{n-1}}^{B^{n}-1} \ln \left(1+\frac{1}{k B+d}\right)
$$

Table 1: Benford's distribution

\begin{tabular}{lcll}
\hline Number & $\begin{array}{l}\text { First } \\
\text { Digit }\end{array}$ & $\begin{array}{l}\text { Second } \\
\text { Digit }\end{array}$ & $\begin{array}{l}\text { Third } \\
\text { Digit }\end{array}$ \\
\hline \hline $\mathbf{0}$ & - & 0.120 & 0.102 \\
\hline $\mathbf{1}$ & 0.301 & 0.114 & 0.101 \\
\hline $\mathbf{2}$ & 0.176 & 0.109 & 0.101 \\
\hline $\mathbf{3}$ & 0.125 & 0.104 & 0.101 \\
\hline $\mathbf{5}$ & 0.097 & 0.100 & 0.100 \\
\hline $\mathbf{6}$ & 0.079 & 0.097 & 0.100 \\
\hline $\mathbf{7}$ & 0.067 & 0.093 & 0.099 \\
\hline $\mathbf{8}$ & 0.058 & 0.090 & 0.099 \\
\hline $\mathbf{9}$ & 0.051 & 0.088 & 0.099 \\
\hline $\mathbf{S}$ & 0.046 & 0.085 & 0.098 \\
\hline
\end{tabular}

Source: Watrin, 2008

Other mathematical properties of Benford's law are as follows:

- Multiplication of Benford's distribution by any constant results in the same distribution

- Can be applied to all numerical systems

- Multiplication, division, squaring, addition and subtraction of Benford's distribution results again in the Benford's distribution (Watrin, 2008) 
Benford's law can be used to detect these data manipulations:

- Rounding financial performance by managers, for example roundings up the profit from 789,000 to 800,000

- Rounding up net income and EPS (earnings per share)

- Rounding losses down (Nigrini, pg 56, 1997)

- Duplication of financial figures such as invoices

- Deleting data

- Rewriting values

In order to use of Benford's law, data should meet the following conditions:

- All the data in the file have to be in the same units

- There has to be a data limitation of the maximum and minimum values

- Data cannot be numbers used for identification, and numbers and numbers which have been generated randomly

- Data should include a rather small number. (TPA Horwath, p.3, 2011)

- It is desirable to have more data files

- Data should not be influenced by psychology, such as prices ending in the number 99

It is appropriate to use data that have a mean greater than the median, and a positive kurtosis. In general, the larger the ratio of mean and median, the more suitable the data is for Benford's test (Durtschi, Hillison, Pacini, p.8, 2004)

In the following table there are types of data, which can be used for the application of Benford's test

Table 2: Suitability of Data for Benford's test

\begin{tabular}{|l|l|}
\hline Suitable data & Unsuitable data \\
\hline Accounts payable & Numbers of checks \\
\hline Accounts receivable & Numbers of invoices \\
\hline Wages & ZIP Codes \\
\hline Sales & Psychological prices (e.g. 999) \\
\hline Expenditures & ATM withdrawals \\
\hline Whole year transaction & Thefts \\
\hline
\end{tabular}

Source: Durtshi, Hillison, Pacini, 2004

Another limitation of Benford's law are types of fraud which cannot be detected by utilizing this procedure. Very simply Benford's law will help us determine whether the overall data set of observations were added, removed, or vice versa. Concerning transactions, which were not recorded, such as a bribe, stealing assets, or duplicate transactions, such as an invoice number, Benford's test cannot be applied. Benford's test also does not help us to detect fictitious employees or the same bank account numbers. (Durtschi, Hillison, Pacini, p.8, 2004).

\section{Results of secondary analysis}

In the field of applying the Benford's law to the macroeconomic data were three studies were previously published. The first "On the Application of Benford's Law to International Macroeconomic Statistics" was published in 2007. The authors focus on testing data in relation to the GDP development of the OECD and African countries. The conclusions were as follows: 1) The majority of the data converges to Benford's distribution, 2) Benford's can serve as an indicator of poor quality, and data manipulation (Nye, Moul, 2007). 
The results of the previous study were reviewed by an economist of the International Monetary Fund in the article "Benford's Law and Macroeconomic Data Quality". The authors tested the macroeconomic data of 80 countries and compared the results with another method of assessing the quality of macroeconomic data, with the IMF's Data Assessment Framework, under which the ranking of countries are compiled according to the quality of statistical data (Data Dissemination Reports on the Observance Standards and Codes). The study's findings were as follows: 1) Data for some countries do not conform to Benford's distribution, although their statistical data on the ranking of the International Monetary Fund was reported as good (Japan, Finland), 2) non-conformity to Benford's may be caused by structural changes in the economy, the adjustment of seasonality and other macro-economic transformations

Recently published studies from 2011 "Fact and Fiction in EU Governmental Economics Data" examined the national accounts of the EU members countries on data relating to the implementation of the Stability and Growth Pact: Government deficit and debt, Government revenue, expenditure and main aggregates, GDP and its main components, Balance sheet, consolidated assets and liabilities

The authors developed the ranking of countries according to the average deviation of the chisquare test results. The conclusions of the study are as follows: 1) The largest deviations from Benford's distribution data were shown in Greece, Romani and Latvia, while the lowest deviation shown was in the Netherlands and from non Euro coutries such as Hungary and the Czech Republic (which was tested for the first time), and Poland, 2) Benford's test can be used as a first instance test, which may indicate the manipulation of data.

The authors of all three studies agree on the fact that the application Benford's to the macroeconomic data can help us to identify the data with a higher probability of manipulation; it is necessary to take into account the constraints that arise from its use, especially erroneous results due to structural changes in the economy, adjusted for seasonality and macroeconomic transformation.

\section{Analysis of primary data}

In this section we will apply Benford's law to the data published by the Czech Statistical Office on foreign trade during the period 1996 to 2012, specifically to the export, import of goods and trade balance. Difference between export and import defines the trade balance, which can be active or passive, and explains whether the state imports or exports more. The trade balance is often mentioned by the media as one of the indicators of economic performance.

The methodology for the data collection of the CSO is as follows:

Export

The export value of goods sent abroad, and crossed the state border for the purpose of permanent or temporary retention abroad. Total exports consist of exports to the EU and exports to countries outside the EU.

Import

Import value of goods received from abroad and crossed the state border for the purpose of permanent or temporary retention at home. Total imports consist of imports from the EU and imports from countries outside the EU. 
The Czech Statistical Office publishes data for individual months, so the sample test data for export and import will contain 204 individual items, and a total of 408 items will be tested. All values are in Czech currency. The currency can not influence the results of Benford's test, because according to basic the parameters of Benford's distribution, multiplying a whole set of numbers by a constant leads back to Benford's distribution. For testing convergence with Benford's law we will use the $\mathrm{Z}$ test, which can be calculated as following:

$Z=\frac{\left(\left|p_{0}-p_{e}\right|-1 / 2 n\right)}{\left(\left(p_{e} *\left(1-p_{e}\right) / n\right)\right)^{1 / 2}}$

Where:

$\mathrm{p}_{0}-$ is the observed proportion in the dataset

$\mathrm{p}_{\mathrm{e}}$ - is the expected proportion based on Benford's law

$\mathrm{n}$ - is the number of observations (the term $1 /(2 \mathrm{n})$ is a continuity correction factor and is used only when it is a smaller than the absolute value term)

The Z-Stat shows the statistical significance of the difference between the two proportions. The significance takes into account the size of the difference (over or under), the expected proportion, and the sample size. Scores above 1.96 are significant at the 0.05 level, and above 2.57 are significant at the 0.01 level.

For investigating convergence of real data-sets to the Benford distribution we can use other statistical tools like the chi-square test or mean absolute deviation. The result of utilizing each tool shows a statistically significant correlation. $\mathrm{Z}$ statistic measures the deviations of frequency of the digits separately, whereas the mean absolute deviation and chi-square values evaluate the deviation of all digits as a whole (Henselmann,Scherr, Ditter, 2012).

\subsection{Results for export}

a) At the 0.05 level of significance, we test the following hypothesis: $\mathrm{H} 0=$ occurrence of each digit in the first place converges to the Benford's distribution

$\mathrm{H} 1$ = occurrence of each digit in the first place does not converge to the Benford's distribution.

Table 3: Results for the first digit of data regarding Czech exports

\begin{tabular}{|r|r|r|r|r|r|}
\hline \multicolumn{1}{|l|}{ Digit } & \multicolumn{1}{|l|}{ Empirical } & \multicolumn{1}{l|}{ Benford } & \multicolumn{1}{l|}{ Diff. } & \multicolumn{1}{l|}{ Abs. Diff } & \multicolumn{1}{l|}{ stat } \\
\hline $\mathbf{1}$ & 0.431 & 0.301 & 0.130 & 0.130 & 3.982 \\
\hline $\mathbf{2}$ & 0.245 & 0.176 & 0.069 & 0.0649 & 2.496 \\
\hline $\mathbf{3}$ & 0.00 & 0.125 & -0.125 & 0.125 & 5.291 \\
\hline $\mathbf{4}$ & 0.039 & 0,097 & -0.058 & 0.058 & 2.667 \\
\hline $\mathbf{5}$ & 0.064 & 0.079 & -0.015 & 0.015 & 0.688 \\
\hline $\mathbf{6}$ & 0.044 & 0.067 & -0.023 & 0.023 & 1.165 \\
\hline $\mathbf{7}$ & 0.069 & 0.058 & 0.011 & 0.011 & 0.500 \\
\hline $\mathbf{8}$ & 0.049 & 0.051 & -0.002 & 0.002 & 0.138 \\
\hline $\mathbf{9}$ & 0.059 & 0.046 & 0.013 & 0.013 & 0.725 \\
\hline
\end{tabular}

Source: Author

The test showed high levels of the $\mathrm{Z}$ statistics in particular with the numbers 1, 2, 3, 4, which means that we have to reject $\mathrm{H} 0$ at this level of significance. 
Figure 1: Graphical inspection of data (empirical vs Benford)

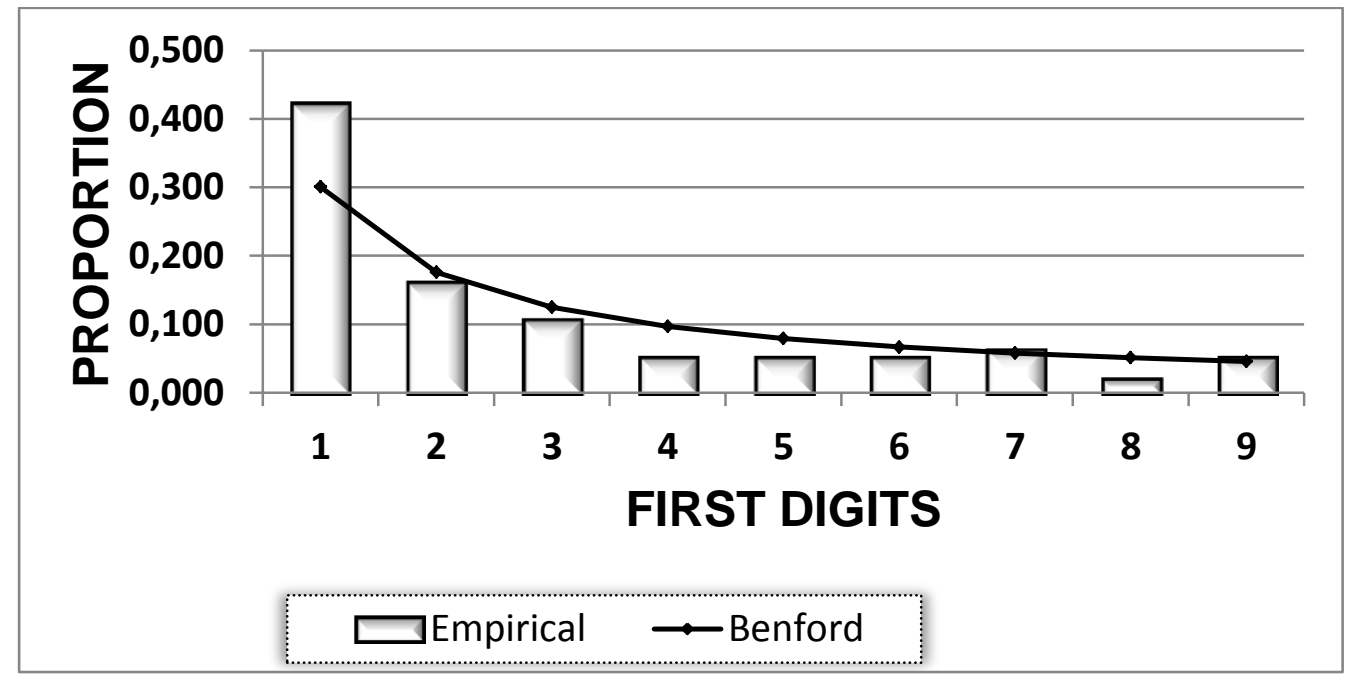

Source: Author

b) At the 0.05 level of significance, we test the following hypothesis: $\mathrm{H} 0=$ occurrence of all individual digits on the second position converges to the Benford's distribution $\mathrm{H} 1$ = occurrence of each digit in the second place do not converge to the Benford's distribution

Table 4: Results for the second digit of data regarding Czech exports

\begin{tabular}{|r|r|r|r|r|r|}
\hline \multicolumn{1}{|l|}{ Digit } & \multicolumn{1}{|l|}{ Empirical } & \multicolumn{1}{l|}{ Benford } & \multicolumn{1}{l|}{ Diff. } & \multicolumn{1}{l|}{ Abs. Diff } & \multicolumn{1}{l|}{ Z stat } \\
\hline $\mathbf{0}$ & 0.147 & 0.120 & 0.027 & 0.027 & 1.097 \\
\hline $\mathbf{1}$ & 0.152 & 0.114 & 0.038 & 0.038 & 1.601 \\
\hline $\mathbf{2}$ & 0.103 & 0.109 & 0.006 & 0.006 & 0.157 \\
\hline $\mathbf{3}$ & 0.069 & 0.104 & -0.036 & 0.036 & 1.554 \\
\hline $\mathbf{4}$ & 0.074 & 0.100 & -0.027 & 0.027 & 1.157 \\
\hline $\mathbf{5}$ & 0.103 & 0.097 & 0.006 & 0.006 & 0.184 \\
\hline $\mathbf{6}$ & 0.093 & 0.093 & 0.000 & 0.000 & 0.011 \\
\hline $\mathbf{7}$ & 0.078 & 0.090 & -0.012 & 0.012 & 0.405 \\
\hline $\mathbf{8}$ & 0.098 & 0.088 & 0.010 & 0.010 & 0.405 \\
\hline $\mathbf{9}$ & 0.083 & 0.085 & -0.002 & 0.002 & 0.085 \\
\hline
\end{tabular}

Source: Author

c) The $\mathrm{Z}$ test did not show any value above 1.96 . We cannot reject $\mathrm{H} 0$. 
Figure 2: Graphical inspection of data (empirical vs Benford)

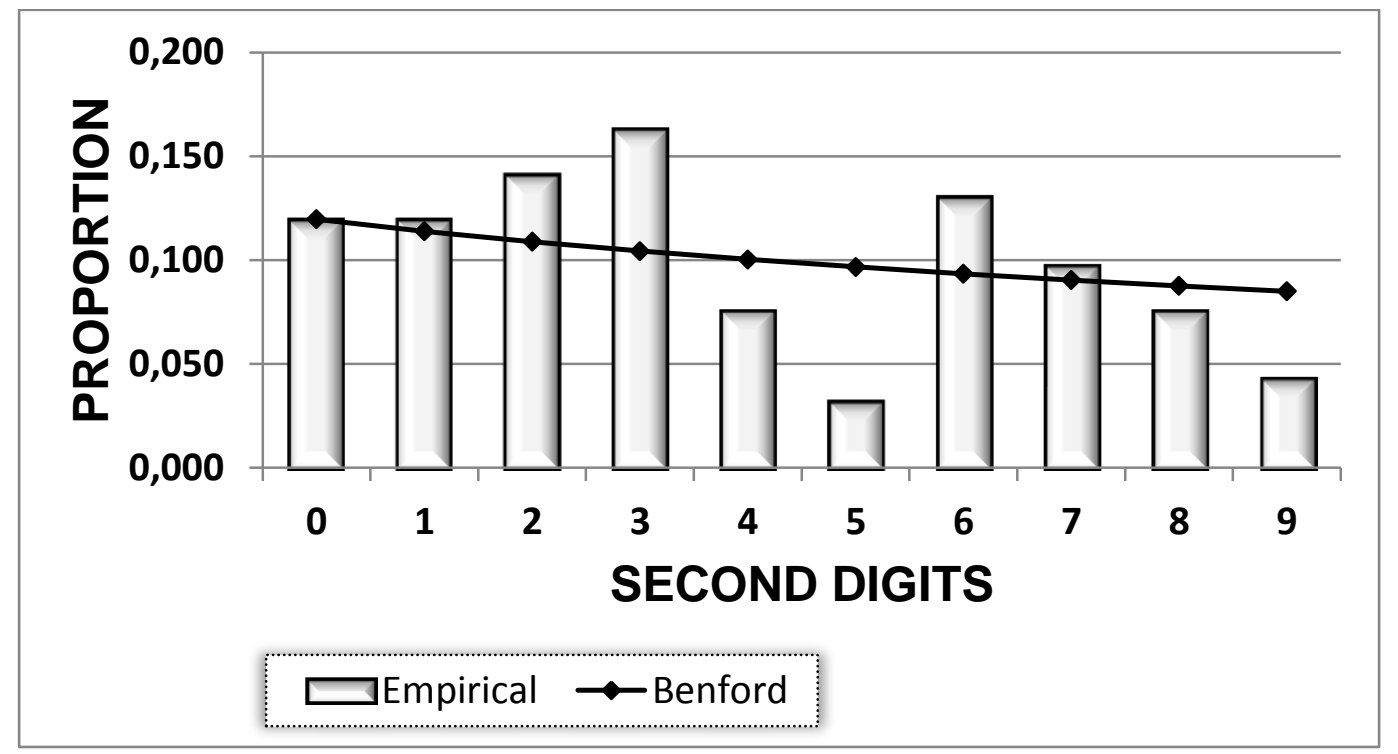

Source: Author

\subsection{Results for import}

a) At the 0.05 level of significance, we test the following hypothesis: $\mathrm{H} 0=$ occurrence of each digit in the first place converges to the Benford's distribution

$\mathrm{H} 1$ = occurrence of each digit in the first place does not converge to the Benford's distribution.

Table 5: Results for the first digit of data regarding Czech imports

\begin{tabular}{|r|r|r|r|r|r|}
\hline \multicolumn{1}{|l|}{ Digit } & \multicolumn{1}{|l|}{ Empirical } & \multicolumn{1}{l|}{ Benford } & \multicolumn{1}{l|}{ Diff. } & \multicolumn{1}{l|}{ Abs. Diff } & \multicolumn{1}{l|}{ Z stat } \\
\hline $\mathbf{1}$ & 0.529 & 0.301 & 0.228 & 0.228 & 7.035 \\
\hline $\mathbf{2}$ & 0.216 & 0.176 & 0.040 & 0.040 & 1.393 \\
\hline $\mathbf{3}$ & 0.000 & 0.125 & -0.125 & 0.125 & 5.291 \\
\hline $\mathbf{4}$ & 0.000 & 0.097 & -0.097 & 0.097 & 2.761 \\
\hline $\mathbf{5}$ & 0.025 & 0.079 & -0.055 & 0.055 & 2.762 \\
\hline $\mathbf{6}$ & 0.074 & 0.067 & 0.007 & 0.007 & 0.236 \\
\hline $\mathbf{7}$ & 0.078 & 0.058 & 0.020 & 0.020 & 1.099 \\
\hline $\mathbf{8}$ & 0.059 & 0.051 & 0.008 & 0.008 & 0.339 \\
\hline $\mathbf{9}$ & 0.020 & 0.046 & -0.026 & 0.026 & 1.620 \\
\hline
\end{tabular}

Source: Author

The test showed high levels of the $\mathrm{Z}$ statistics in particular with the numbers $1,3,4,5$, which means that we have to reject $\mathrm{H} 0$ at the level of significance. 
Figure 3: Graphical inspection of data (empirical vs Benford)

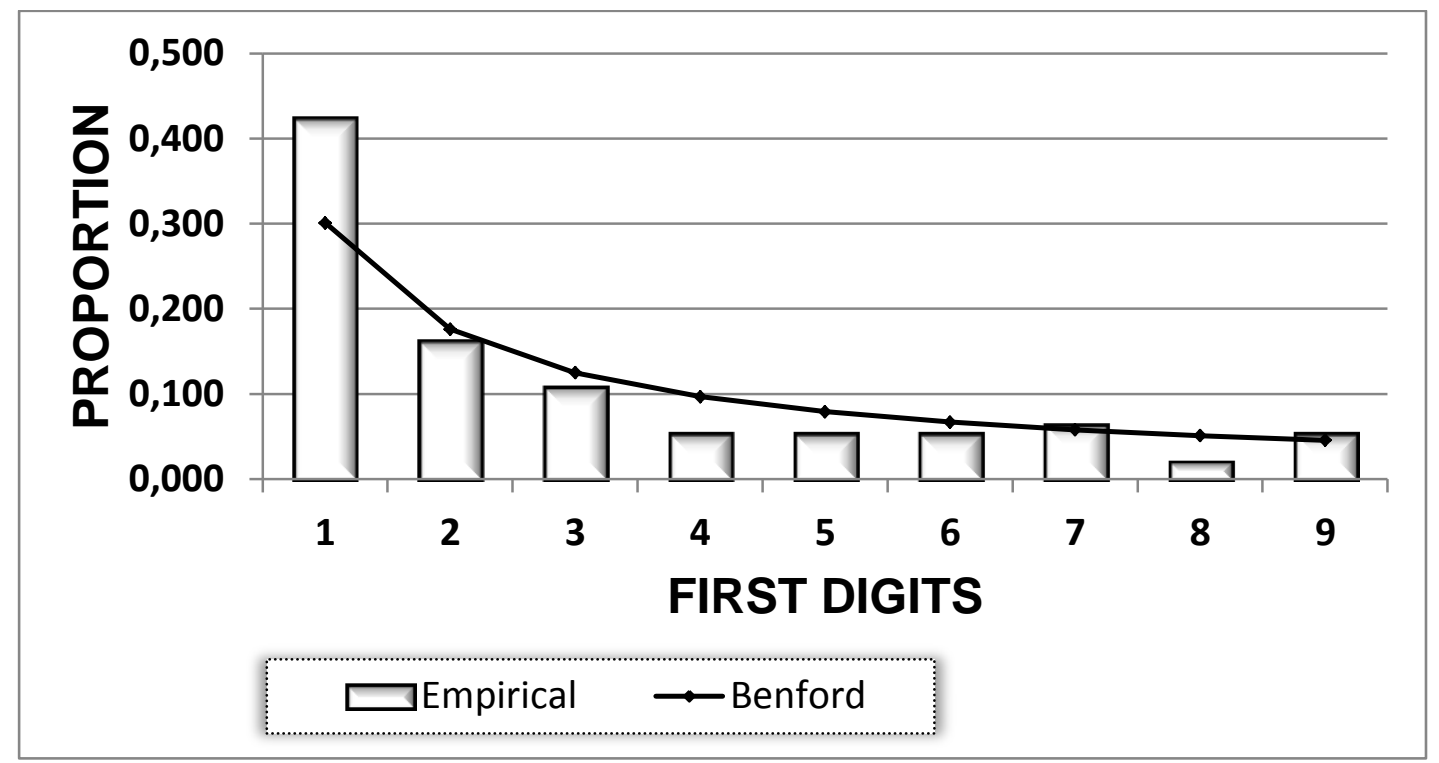

Source: Author

b) At the 0.05 level of significance, we test the following hypothesis: $\mathrm{H} 0=$ occurrence of all individual digits on the second position converges to the Benford's distribution $\mathrm{H} 1$ = occurrence of each digit in the second place do not converge to the Benford's distribution

Table 6: Results for the second digit of data regarding Czech imports

\begin{tabular}{|r|r|r|r|r|r|}
\hline \multicolumn{1}{|l|}{ Digit } & \multicolumn{1}{|l|}{ Empirical } & \multicolumn{1}{l|}{ Benford } & \multicolumn{1}{l|}{ Diff. } & \multicolumn{1}{l|}{ Abs. Diff } & \multicolumn{1}{l|}{ stat } \\
\hline $\mathbf{0}$ & 0.172 & 0.120 & 0.052 & 0.052 & 2.175 \\
\hline $\mathbf{1}$ & 0.137 & 0.114 & 0.023 & 0.023 & 0.940 \\
\hline $\mathbf{2}$ & 0.137 & 0.109 & 0.028 & 0.028 & 1.197 \\
\hline $\mathbf{3}$ & 0.083 & 0.104 & -0.021 & 0.021 & 0.867 \\
\hline $\mathbf{4}$ & 0.054 & 0.100 & -0.046 & 0.046 & 2.089 \\
\hline $\mathbf{5}$ & 0.132 & 0.097 & 0.036 & 0.036 & 1.606 \\
\hline $\mathbf{6}$ & 0.088 & 0.093 & -0.005 & 0.005 & 0.132 \\
\hline $\mathbf{7}$ & 0.074 & 0.090 & -0.017 & 0.017 & 0.716 \\
\hline $\mathbf{8}$ & 0.044 & 0.088 & -0.043 & 0.043 & 2.072 \\
\hline $\mathbf{9}$ & 0.078 & 0.085 & -0.007 & 0.007 & 0.211 \\
\hline
\end{tabular}

Source: Author

The test showed high levels of the $\mathrm{Z}$ statistics in particular with the numbers $0,4,8$ which means that we have to reject $\mathrm{H} 0$ at the level of significance. 
Figure 4: Graphical inspection of data (empirical vs Benford)

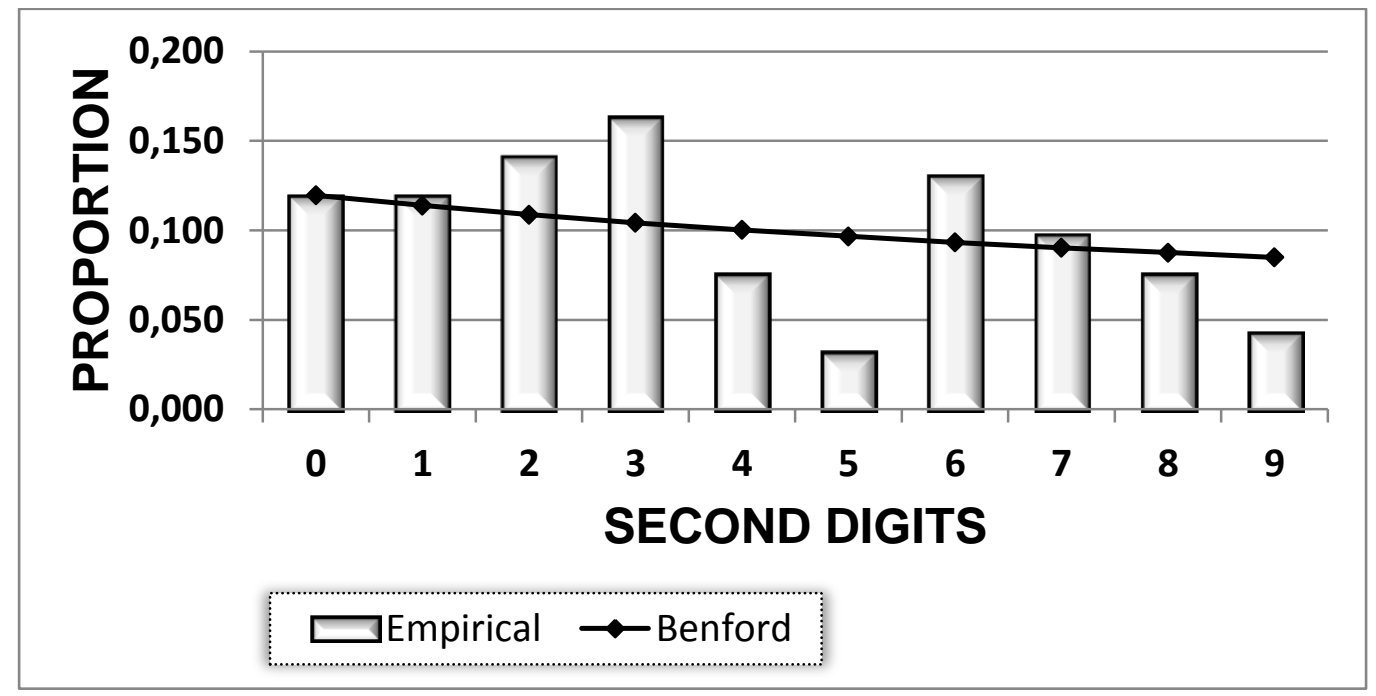

Source: Author

\subsection{Results for trade balance}

a) At the 0.05 level of significance, we test the following hypothesis: $\mathrm{H} 0=$ occurrence of each digit in the first place converges to the Benford's distribution $\mathrm{H} 1$ = occurrence of each digit in the first place does not converge to the Benford's distribution.

Table 7: Results for the first digit of data regarding Czech trade balance

\begin{tabular}{|r|r|r|r|r|r|}
\hline Digit & Empirical & Benford & Difference & AbsDiff & Z-stat \\
\hline $\mathbf{1}$ & 0.402 & 0.301 & 0.101 & 0.101 & 3.066 \\
\hline $\mathbf{2}$ & 0.118 & 0.176 & -0.058 & 0.058 & 2.100 \\
\hline $\mathbf{3}$ & 0.098 & 0.125 & -0.027 & 0.027 & 1.056 \\
\hline $\mathbf{4}$ & 0.054 & 0.097 & -0.043 & 0.043 & 1.957 \\
\hline $\mathbf{5}$ & 0.088 & 0.079 & 0.009 & 0.009 & 0.349 \\
\hline $\mathbf{6}$ & 0.054 & 0.067 & -0.013 & 0.013 & 0.604 \\
\hline $\mathbf{7}$ & 0.074 & 0.058 & 0.016 & 0.016 & 0.800 \\
\hline $\mathbf{8}$ & 0.039 & 0.051 & -0.012 & 0.012 & 0.615 \\
\hline $\mathbf{9}$ & 0.074 & 0.046 & 0.028 & 0.028 & 1.731 \\
\hline
\end{tabular}

Source: Author

The test showed high levels of the $\mathrm{Z}$ statistics in particular with the number 1 and 2 which means that we have to reject $\mathrm{H} 0$ at the level of significance. 
Figure 5: Graphical inspection of data (empirical vs Benford)

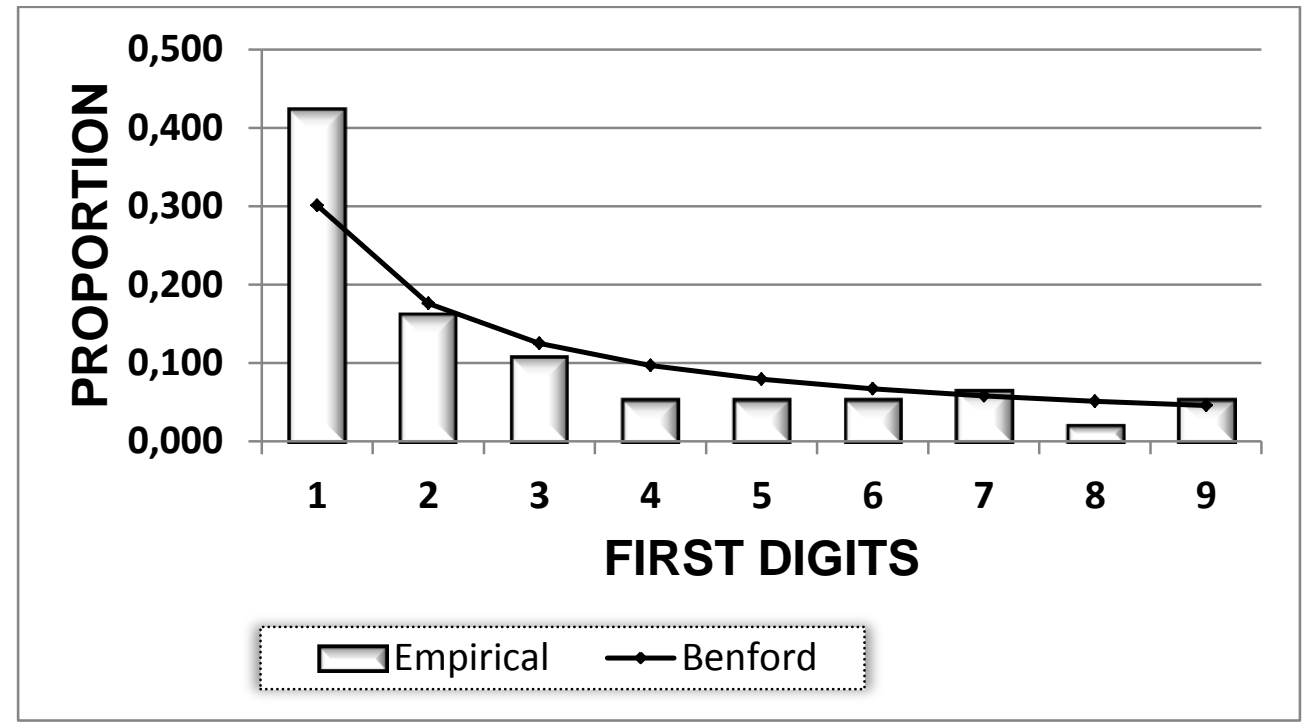

Source: Author

b) At the 0.05 level of significance, we test the following hypothesis: $\mathrm{H} 0=$ occurrence of all individual digits on the second position converges to the Benford's distribution $\mathrm{H} 1$ = occurrence of each digit in the second place do not converge to the Benford's distribution

Table 8: Results for the second digit of data regarding Czech trade balance

\begin{tabular}{|c|c|c|c|c|c|}
\hline Digit & Empirical & Benford & Difference & AbsDiff & Z-stat \\
\hline $\mathbf{0}$ & 0.137 & 0.120 & 0.018 & 0.018 & 0.666 \\
\hline 1 & 0.113 & 0.114 & -0.001 & 0.001 & 0.051 \\
\hline 2 & 0.118 & 0.109 & 0.009 & 0.009 & 0.292 \\
\hline 3 & 0.118 & 0.104 & 0.013 & 0.013 & 0.508 \\
\hline 4 & 0.108 & 0.100 & 0.008 & 0.008 & 0.242 \\
\hline 5 & 0.083 & 0.097 & -0.013 & 0.013 & 0.527 \\
\hline 6 & 0.108 & 0.093 & 0.014 & 0.014 & 0.590 \\
\hline 7 & 0.093 & 0.090 & 0.003 & 0.003 & 0.017 \\
\hline 8 & 0.064 & 0.088 & -0.024 & 0.024 & 1.081 \\
\hline 9 & 0.059 & 0.085 & -0.026 & 0.026 & 1.215 \\
\hline
\end{tabular}

Source: Author

The Z- stat shows that we cannot reject $\mathrm{H} 0$. 
Figure 6: Graphical inspection of data (empirical vs Benford)

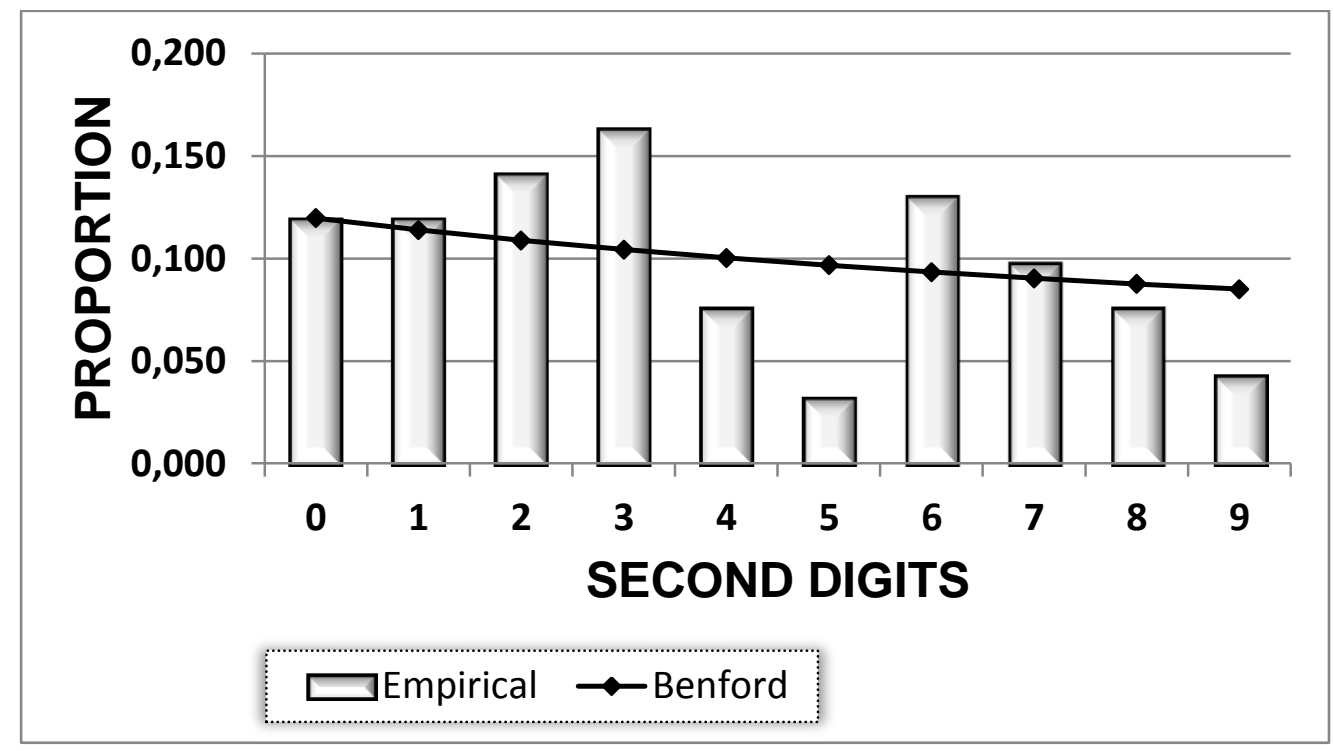

Source: Author

The only data which conformed to the Benford's distribution were the second digits of trade balance and of export. These results can lead us to suspect a poor quality of data, or data manipulation. With the intention of confirming the hypothesis about data manipulation it is necessary to carry out a base audit. Discrepancies can be also caused by the reasons that we have stated in the conclusions of the analysis of secondary sources.

\section{Conclusions}

The article summarizes the current theory regarding Benford's Law and applies this theory to the governmental macroeconomic data. An analysis of the available literature, and empirical studies which lead to the synthesis of the basic theory, which itself is necessary to properly apply Benford's Law, were the basis of the methodology utilized in the theoretical section. We have tested hypotheses about the convergence of empirical data against Benford's distribution in the practical section. We have tested the first and second digits separately. The $\mathrm{Z}$ test is used as the test criterion. Data from 2013 were utilized for testing.

The test results show that the first digit demonstrates a significant deviation from Benford's distribution. These findings do not automatically equate to the suspicion of the manipulation of the governmental macroeconomic data. When interpreting the results of the Czech case, the author inclines towards theses published in the following articles On the Application of Benford's Law to International Macroeconomic Statistics (Nye, Moul, 2007) and Benford's Law and Data Quality Macroeconomics (Gonzales, Pastor, 2010). Deviations in data from Benford's distribution may be caused by a structural economic shift during the period 19962012 , and not by the poor quality of data.

In order to be complete, it should also be noted that the quality of data affects all macroeconomic transformations as well as seasonal adjustments. Benford's test is also recommended to be applied to larger data samples.

Benford's test can be used as an indicative test of the first instance, which we can use to identify the increased risk of manipulation, for adequate assurances we have to do a subsequent audit. Benford's test can be seen as a tool for increasing the effectiveness of the 
control data. It allows very quickly and inexpensively to identify potentially suspicious data, on which we can focus the audit work.

\section{Poděkování}

Tento článek vznikl za podpory VGS 2013 K02 Finanční a účetní studie a jejich praktické aplikace.

\section{References}

[1] BARROW, D. J., 2011. Benford's very strange law. Lecture. Gresham College [online]. Available at: http://www.youtube.com/watch?v=4iz4EHriYz0\&feature=related

[2] BERHGER A. and P. T. HILL, 2011. A Basic Theory of Benford's Law [online]. Probability Surveys MIT 2011. Avaible at: www.ijournals.org/ ps/include/getdoc.php?id=696\&article

[3] CARSLAW, C. A. P., 1988. Anomalies in Income Numbers: Evidence of Goal Oriented Behavior. Accounting Review, 63(2), 321-327. ISSN 00014826.

[4] DECKER, J., M. MYAGKOV and C. P. ORDESHOOK, 2011. The irrelevance of Benford's law for detecting fraud in election. Capotech/MIT Voting Technology Project, Working Paper [online]. Available at: http://www.vote.caltech.edu/drupal/files/ rpeavt_paper/benford_pdf_4b97cc5b5b.pdf

[5] DURTSCHI, C., W. HILLISON and C. PACINI, 2004. The effective use of Benford's law to assist in detecting fraud in accounting data. Journal of Forensic accounting [online]. 5, 17-34. Available at: http:/www.uic.edu/classes/actg/actg593/Readings/ Auditing/The-Effective-Use-Of-Benford's-Law-To-Assist-In-Detecting-Fraud-InAccounting-Data.pdf

[6] GONZALES, J. and G. PASTOR, 2009. Benford's Law and Macroeconomic Data Quality. International Monetary Fund, Working Paper [online]. Available at: http://papers.ssrn.com/sol3/papers.cfm?abstract_id=1356437

[7] HENSELMANN, K., E. SCHERR and D. DITTER, 2012. Applying Benford's Law to Individual Financial Reports. An Empirical Investigation on the Basis of SEC XBRL filings. Working Papers in Accounting Valuation Auditing, Nr. 2012-1. ISSN 1867-7932.

[8] HILL, T. P., 1998. The First Digit Phenomenon. American Scientist, 86(4), 358-363. ISSN 0003-0996.

[9] HILL, T. P., 1995a. A Statistical Derivation of the Significant-Digit Law. Statistical Science, 10(4), 354-363. ISSN 08834237.

[10] HILL, T. P., 1995b. Base-Invariance Implies Benford's Law. Proceedings of the American Mathematical Society, 123(3), 887-895. ISSN 1088-6826.

[11] NIGRINI, M., 1993. Can Benford's Law be used in Forensic Accounting? Balance Sheet [online]. June 1993. Available at: http://www.nigrini.com/benfordslaw.htm

[12] NIGRINI, M. and L. MITTERMAIER, 1997. The Use of Benford's Law as an Aid in Analytical Procedures. Auditing A Journal of Practice and Theory, 16(2), 52-67. ISSN 0278-0380.

[13] Nové způsoby odhalování manipulace s účetními daty, 2011. TPA HORWATH [online]. Available at: http://www.tpa-horwath.cz/upload/files/PDF/Manipulace_s_ucetnimi_ daty_JSK_10_08.pdf 
[14] NYE, J. and C. MOUL, 2007. The Political Economy of Numbers: On the Application of Benford's Law to International Macroeconomic Statistics. B. E. Journal of Macroeconomics, 7(1). Available at: http://www.bepress.com/bejm/vol7/iss1/art17

[15] RAUCH, B., M. GÖTTSCHE and G. BRÄHLER, 2011. Fact and Fiction in EU Governmental Economics Data. German Economics Revue, 12(3), 243-255. ISSN 14680475 .

[16] WATRIN, CH., 2008. Benfords Law: An Instrument for Selection Tax Audit Targets? Review of Managerial Science [online]. 2(3), 219-237. Available at: http://www.springerlink.com/content/296p91r570034k25/?MUD=MP 